\title{
NOTE ON THE RESOLVABILITY OF THE MINORS OF A COMPOUND DETERMINANT.
}

By Sir Thomas Muir, LL.D.

(1) The theorem which is usually made the basis of investigation on this subject is that exemplified by Spottiswoode* in 1853 and formally enunciated and established by Franke and Borchardt $\dagger$ in 1862. It is in effect that any k-line minor of the $m^{\text {th }}$ compound of $\left|a_{1 n}\right|$ is equal to

$$
\mathrm{K} \cdot\left|a_{1 n}\right|^{k-(n-1) m .}
$$

$\mathrm{K}$ being the complementary of the corresponding minor in the $(n-m)^{\text {th }}$ compound. The theorem is of course directly useful for the end in view when $k>(n-1)_{m}$; in other cases it may turn out indirectly useful, but only because the said corresponding minor occasionally lends itself more readily to decomposition than the minor actually set.

(2) There is one case, however, in which it is of no avail at all; namely, where

$$
k=(n-1)_{m} \text { and } n=2 m,
$$

for then it takes an illusory form, all the information given by it being that the minor in question is equal to itself. The existence of this case makes the general problem difficult of treatment; and it is consequently desirable for future work to know how the question of resolvability stands in regard to it. The instance of it where

$$
n=4, \quad m=2, \quad k=3,
$$

is the simplest, but, as there are then 400 minors to be adjudicated on, considerable instruction necessarily results from examination of it. If the basic determinant be taken in the form

$$
\left|a_{1} b_{2} c_{3} d_{4}\right|
$$

the 400 in question are the three-line minors of

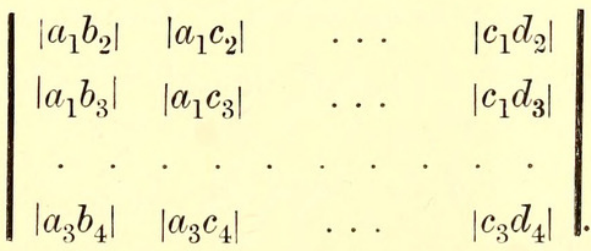

$$
\begin{aligned}
& \text { * ‘Crelle's Journ.,' li, pp. 366-368. } \\
& \text { + ‘Crelle's Journ.,' lxi, pp. 350-358. }
\end{aligned}
$$


(3) The most numerous and the most interesting of them are those that are irresolvable. As a typical example we may take

$$
\begin{aligned}
& 125 \\
& 125
\end{aligned} \text { i.e. }\left|\begin{array}{lll}
\left|a_{1} b_{2}\right| & \left|a_{1} b_{3}\right| & \left|a_{2} b_{4}\right| \\
\left|a_{1} c_{2}\right| & \left|a_{1} c_{3}\right| & a_{2} c_{4} \mid \\
\left|b_{1} d_{2}\right| & \left|b_{1} d_{3}\right| & b_{2} d_{4} \mid
\end{array}\right|,
$$

the irresolvability of which is implicated in the equality

$$
|| a_{1} b_{2}|| a_{1} c_{3}|| b_{2} d_{4}||=\left|a_{1} b_{2} c_{4}\right|\left|a_{1} b_{2} d_{3}\right|+a_{1} b_{2}\left|a_{1} b_{2} c_{3} d_{4}\right| .
$$

One way of proving this may be put shortly as follows. In the given determinant

$$
\begin{aligned}
\text { the cofactor of }\left|b_{2} d_{4}\right| & =a_{1}\left|a_{1} b_{2} c_{3}\right|, \\
\text { the cofactor of }\left|a_{2} c_{4}\right| & =b_{1}\left|b_{1} a_{2} d_{3}\right|, \\
\text { and the cofactor of }\left|a_{2} b_{4}\right| & =a_{1}\left|b_{1} a_{2} d_{3}\right|+c_{1}\left|a_{1} b_{2} d_{3}\right| *,
\end{aligned}
$$

so that the determinant

$$
\begin{aligned}
=\left|a_{1} b_{2} d_{3}\right| & \left\{c_{1}\left|a_{2} b_{4}\right|-b_{1}\left|a_{2} c_{4}\right|\right. \\
& +a_{1}\left\{\left|b_{2} d_{4}\right|\left|a_{1} b_{2} c_{3}\right|+\left|a_{2} b_{4}\right|\left|b_{1} c_{2} d_{3}\right|\right\} .
\end{aligned}
$$

By increasing the first part of this by

$$
\left|a_{1} b_{2} d_{3}\right| \cdot a_{1} \cdot\left|b_{2} c_{4}\right|
$$

and diminishing the second by the same, the former becomes

$$
\left|a_{1} b_{2} d_{3}\right|\left|a_{1} b_{2} c_{4}\right|
$$

and the latter becomes

$$
a_{1}\left\{\left|b_{2} d_{4}\right|\left|b_{2} a_{1} c_{3}\right|-\left|b_{2} a_{4}\right|\left|b_{2} d_{1} c_{3}\right|-\left|b_{2} c_{4}\right|\left|b_{2} a_{1} d_{3}\right|\right\}
$$

which is readily seen to be equal to

as desired.

$$
a_{1} b_{2}\left|b_{2} d_{4} a_{1} c_{3}\right|
$$

(4) We may note in passing that to the development thus obtained,

there is an alternative form, namely,

$$
\left|a_{1} b_{2} c_{4}\right|\left|a_{1} b_{2} d_{3}\right|+a_{1} b_{2}\left|a_{1} b_{2} c_{3} d_{4}\right|
$$

$$
\left|a_{1} b_{2} c_{3}\right|\left|a_{1} b_{2} d_{4}\right|+a_{2} b_{1}\left|a_{1} b_{2} c_{3} d_{4}\right| \text {. }
$$

The equivalence of the two is established by noting that their difference

$$
\left|a_{1} b_{2} c_{4}\right|\left|a_{1} b_{2} d_{3}\right|-\left|a_{1} b_{2} c_{3}\right|\left|a_{1} b_{2} d_{4}\right|+\left|a_{1} b_{2}\right|\left|a_{1} b_{2} c_{3} d_{4}\right|
$$

is the extensional of

$$
c_{4} d_{3}-c_{3} d_{4}+\left|c_{3} d_{4}\right|
$$

which manifestly vanishes.

* This identity used by Binet in 1812 : see. 'Hist.' i, p. 89. 
(5) The distinguishing feature of the equality established in $\S 3$ is the prominence held in it by the collocation of elements $a_{1} b_{2}$; and we see that to every such collocation, thirty-six in all, there corresponds a like equality having on its left an irresolvable minor. In this connection the next point is to ascertain whether there be not other irresolvable minors in which $a_{1} b_{2}$ plays the same part. Observing the positions occupied in

$$
\left|\begin{array}{llll}
a_{1} & a_{2} & a_{3} & a_{4} \\
b_{1} & b_{2} & b_{3} & b_{4} \\
c_{1} & c_{2} & c_{3} & c_{4} \\
d_{1} & d_{2} & d_{3} & d_{4}
\end{array}\right|
$$

by the minors involved in the equality (I) we see that while retaining $a_{1} b_{2}$ unchanged in all its positions we may make $(\alpha)$ interchange of the third row with the fourth, $(\beta)$ interchange of the third column with the fourth, and $(\gamma)$ both of these interchanges simultaneously. Doing this we obtain

(a) ||$\left.a_{1} b_{2}|| a_{1} d_{3}|| b_{3} c_{4} \mid\right\}=\left|a_{1} b_{2} c_{3}\right|\left|a_{1} b_{2} d_{4}\right|+a_{1} b_{2}\left|a_{1} b_{2} d_{3} c_{4}\right|$

$$
\text { i.e. } \quad\left|\begin{array}{l}
125 \\
134
\end{array}\right|=\left|a_{1} b_{2} \epsilon_{3}\right|\left|a_{1} b_{2} d_{4}\right|-a_{1} b_{2}\left|a_{1} b_{2} c_{3} d_{4}\right| \text {. }
$$

( $\beta) ~|| a_{1} b_{2}|| a_{1} c_{4}|| b_{2} d_{3}||=\left|a_{1} b_{2} c_{3}\right|\left|a_{1} b_{2} d_{4}\right|+a_{1} b_{2}\left|a_{1} b_{2} c_{4} d_{3}\right|$

$$
\text { i.e. } \quad\left|\begin{array}{l}
134 \\
125
\end{array}\right|=\left|a_{1} b_{2} c_{3}\right|\left|a_{1} b_{2} d_{4}\right|-a_{1} b_{2}\left|a_{1} b_{2} c_{3} d_{4}\right| \text {. }
$$

( $\gamma) \quad|| a_{1} b_{2}|| a_{1} d_{4}|| b_{2} c_{3}|=| a_{1} b_{2} d_{3}|| a_{1} b_{2} c_{4}\left|+a_{1} b_{2}\right| a_{1} b_{2} d_{4} c_{3} \mid$

i.e. $\quad\left|\begin{array}{ll}134 \\ \text { ind }\end{array}\right|=\left|a_{1} b_{2} c_{4}\right|\left|a_{1} b_{2} d_{3}\right|+a_{1} b_{2}\left|a_{1} b_{2} c_{3} d_{4}\right|$.

There are thus four different irresolvable minors marked out by the collocation $a_{1} b_{2}$, the set of four being most suitably arranged thus :

$$
\begin{aligned}
& \left|\begin{array}{l}
125 \\
125
\end{array}\right|=\left|a_{1} b_{2} c_{4}\right|\left|a_{1} b_{2} d_{3}\right|+a_{1} b_{2}\left|a_{1} b_{2} c_{3} d_{4}\right|=\left|\begin{array}{l}
134 \\
134
\end{array}\right| \\
& \left|\begin{array}{l}
125 \\
134
\end{array}\right|=\left|a_{1} b_{2} c_{3}\right|\left|a_{1} b_{2} d_{4}\right|-a_{1} b_{2}\left|a_{1} b_{2} c_{3} d_{4}\right|=\left|\begin{array}{l}
134 \\
125
\end{array}\right| .
\end{aligned}
$$

As a consequence we know of the existence of 144 irresolvables among the 400 three-line minors of the second compound of $\left|a_{1} b_{2} c_{3} d_{4}\right|$; also that the 144 may be arranged in pairs the members of which are equal.

(6) In turning to resolvables it is convenient to deal first with an equality immediately derivable from (I), namely,

$$
\left|\begin{array}{lll}
\left|a_{1} b_{2}\right| & \left|a_{1} b_{3}\right| & \left|a_{2} b_{3}\right| \\
\left|a_{1} c_{2}\right| & \left|a_{1} c_{3}\right| & \left|a_{2} c_{3}\right| \\
\left|b_{1} d_{2}\right| & \left|b_{1} d_{3}\right| & \left|b_{2} c_{3}\right|
\end{array}\right|=\left|a_{1} b_{2} c_{3}\right|\left|a_{1} b_{2} d_{3}\right|,
$$


got by changing the suffix 4 everywhere into 3 . It is seen to concern the elements of a 4 - by -3 array, and to have its left member conveniently symbolisable by

$$
\left\{\begin{array}{lll}
a_{1} & a_{2} & a_{3} \\
b_{1} & b_{2} & b_{3} \\
c_{1} & c_{2} & c_{3} \\
d_{1} & d_{2} & d_{3}
\end{array}\right.
$$

where the first two rows have a double link of connection and the other two a single link. With the first two still doubly connected, but with different single ends, there is the diagram

giving us the equality

$$
\left\{\begin{array}{lll}
a_{1} & a_{2} & a_{3} \\
b_{1} & b_{2} & b_{3} \\
c_{1} & c_{2} & c_{3} \\
d_{1} & d_{2} & d_{3}
\end{array}\right.
$$

$$
\left|\begin{array}{lll}
\left|a_{1} b_{2}\right| & \left|a_{1} b_{3}\right| & \left|a_{2} b_{3}\right| \\
\left|a_{1} d_{2}\right| & \left|a_{1} d_{3}\right| & \left|a_{2} d_{3}\right| \\
\left|b_{1} c_{2}\right| & \left|b_{1} c_{3}\right| & \left|b_{2} c_{3}\right|
\end{array}\right|=\left|a_{1} b_{2} c_{3}\right| \quad\left|a_{1} b_{2} d_{3}\right|,
$$

so that we have

$$
\begin{aligned}
& 124 \\
& 125
\end{aligned}|=| a_{1} b_{2} c_{3}|| a_{1} b_{2} d_{3}|=| \begin{aligned}
& 124 \\
& 134
\end{aligned} \mid .
$$

As the double-ends might also be at $a_{1} c_{1}, a_{1} d_{1}, b_{1} c_{1}, b_{1} d_{1}, c_{1} d_{1}$; and as the number of 4 -by-3 arrays is 4 ; and as there is as many 3-by-4 arrays equally fruitful; the full number of three-line minors resolvable in this particular way is

$$
2 \times 6 \times 4 \times 2 \text { i.e. } 96 \text {. }
$$

(7) Changing the $d$ 's of the foregoing into $c$ 's, we obtain the familiar equality regarding the adjugate of $\left|a_{1} b_{2} c_{3}\right|$

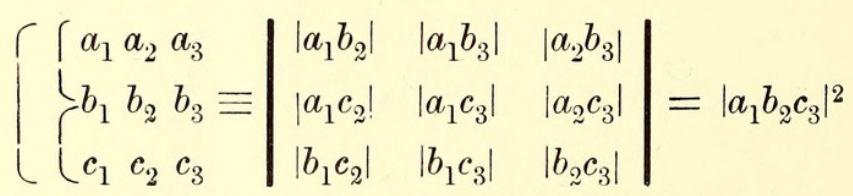

Of this there must be sixteen instances, one corresponding to every primary minor of $\left|a_{1} b_{2} c_{3} d_{4}\right|$.

(8) An example of the next type of resolvable minors is $\begin{array}{r}123 \\ 125\end{array}$, the equality connected with which is 


$$
\left|\begin{array}{lll}
\left|a_{1} b_{2}\right| & \left|a_{1} b_{3}\right| & \left|a_{1} b_{4}\right| \\
\left|a_{1} c_{2}\right| & \left|a_{1} c_{3}\right| & \left|a_{1} c_{4}\right| \\
\left|b_{1} d_{2}\right| & \left|b_{1} d_{3}\right| & \left|b_{1} d_{4}\right|
\end{array}\right|=a_{1} b_{1}\left|a_{1} b_{2} c_{3} d_{4}\right|
$$

and is established in the same way as that of $\S 3$. The left-hand member being symbolisable by

$$
\left(\begin{array}{l|lll}
a_{1} & a_{2} & a_{3} & a_{4} \\
b_{1} & b_{2} & b_{3} & b_{4} \\
c_{1} & c_{2} & c_{3} & c_{4} \\
d_{1} & d_{2} & d_{3} & d_{4}
\end{array}\right.
$$

we may reason in regard to it exactly after the manner of $\S 6$, obtaining first the double result

$$
\left|\begin{array}{l}
123 \\
125
\end{array}\right|=a_{1} b_{2}\left|a_{1} b_{2} c_{3} d_{4}\right|=\left|\begin{array}{l}
123 \\
143
\end{array}\right|
$$

and thereafter the number of such resolvables to be 96 .

(9) Less general than the immediately preceding, although not thence obtainable by substitution, is the equality

$$
\begin{aligned}
& 123 \\
& 123
\end{aligned} \equiv\left|\begin{array}{lll}
\left|a_{1} b_{2}\right| & \left|a_{1} b_{3}\right| & \left|a_{1} b_{4}\right| \\
\left|a_{1} c_{2}\right| & \left|a_{1} c_{3}\right| & \left|a_{1} c_{4}\right| \\
\left|a_{1} d_{2}\right| & \left|a_{1} d_{3}\right| & \left|a_{1} d_{4}\right|
\end{array}\right|=a_{1}^{2}\left|a_{1} b_{2} c_{3} d_{4}\right| .
$$

Here, as in $\S 7$, the change of rows into columns is fruitless, the left-hand member being symbolisable both by

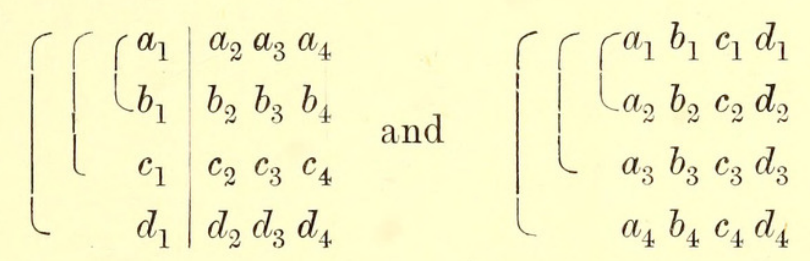

The number of minors so resolvable is manifestly sixteen.

(10) Lastly, by returning to $\S 8$ and changing the $d$ 's into $c$ 's we obtain

$$
|123| \equiv\left|\begin{array}{lll}
\left|a_{1} b_{2}\right| & \left|a_{1} b_{3}\right| & \left|a_{1} b_{4}\right| \\
\left|a_{1} c_{2}\right| & \left|a_{1} c_{3}\right| & \left|a_{1} c_{4}\right| \\
\left|b_{1} c_{2}\right| & \left|b_{1} c_{3}\right| & \left|b_{1} c_{4}\right|
\end{array}\right|=0 .
$$

The construction-symbol for the determinant is either

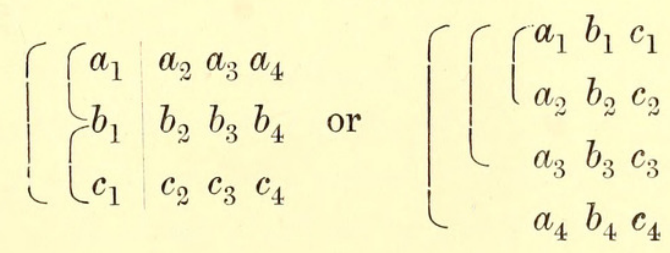


the former showing affinity with the symbol of $\S 8$ and the latter with that of $\S 6$. Using either symbol, we readily infer that the number of vanishing minors is thirty-two.

(11) There thus results the following census:

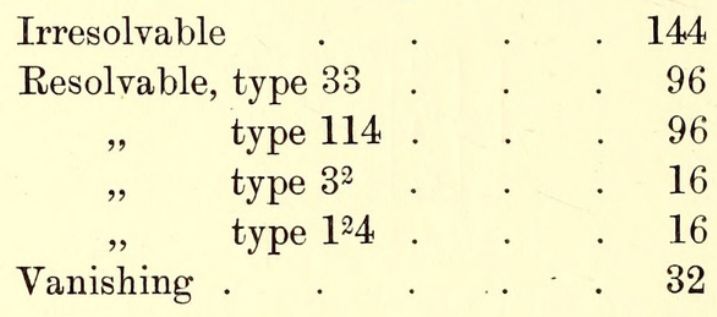

giving the requisite total of 400 . As in the first three groups each minor has an equivalent companion, there are altogether 168 such pairs of equals

Capetown, South Africa,

April 11th, 1917. 


\section{$2 \mathrm{BHL}$ Biodiversity Heritage Library}

Muir, Thomas. 1918. "NOTE ON THE RESOLVABILITY OF THE MINORS OF A COMPOUND DETERMINANT." Transactions of the Royal Society of South Africa 7, 97-102. https://doi.org/10.1080/00359191809519547.

View This Item Online: https://www.biodiversitylibrary.org/item/181304

DOI: https://doi.org/10.1080/00359191809519547

Permalink: https://www.biodiversitylibrary.org/partpdf/175585

\section{Holding Institution}

Smithsonian Libraries

\section{Sponsored by}

Biodiversity Heritage Library

\section{Copyright \& Reuse}

Copyright Status: Not in copyright. The BHL knows of no copyright restrictions on this item.

This document was created from content at the Biodiversity Heritage Library, the world's largest open access digital library for biodiversity literature and archives. Visit BHL at https://www.biodiversitylibrary.org. 